PREPARED FOR THE U.S. DEPARTMENT OF ENERGY, UNDER CONTRACT DE-AC02-76CH03073

PPPL-3622

PPPL-3622

UC-70

High-frequency Probing Diagnostic for Hall Current Plasma Thrusters

by

A.A. Litvak, Y. Raitses, and N.J. Fisch

October 2001

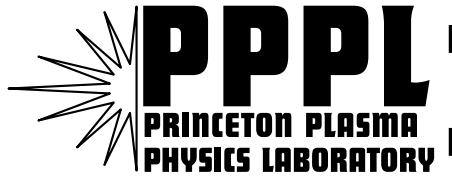

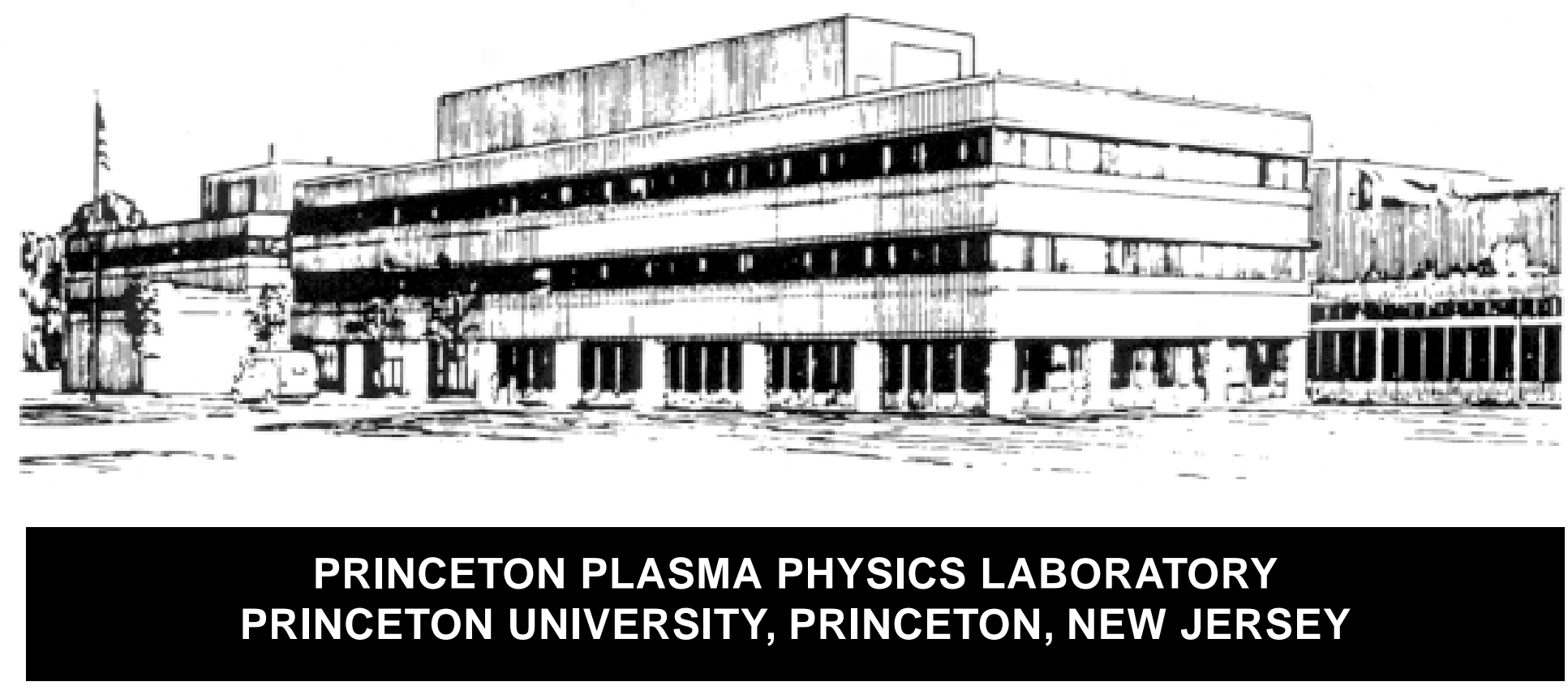




\section{PPPL Reports Disclaimer}

This report was prepared as an account of work sponsored by an agency of the United States Government. Neither the United States Government nor any agency thereof, nor any of their employees, makes any warranty, express or implied, or assumes any legal liability or responsibility for the accuracy, completeness, or usefulness of any information, apparatus, product, or process disclosed, or represents that its use would not infringe privately owned rights. Reference herein to any specific commercial product, process, or service by trade name, trademark, manufacturer, or otherwise, does not necessarily constitute or imply its endorsement, recommendation, or favoring by the United States Government or any agency thereof. The views and opinions of authors expressed herein do not necessarily state or reflect those of the United States Government or any agency thereof.

\section{Availability}

This report is posted on the U.S. Department of Energy's Princeton Plasma Physics Laboratory Publications and Reports web site in Fiscal Year 2002. The home page for PPPL Reports and Publications is: http://www.pppl.gov/pub_report/

DOE and DOE Contractors can obtain copies of this report from:

U.S. Department of Energy

Office of Scientific and Technical Information

DOE Technical Information Services (DTIS)

P.O. Box 62

Oak Ridge, TN 37831

Telephone: (865) 576-8401

Fax: (865) 576-5728

Email: reports@adonis.osti.gov

This report is available to the general public from:

National Technical Information Service

U.S. Department of Commerce

5285 Port Royal Road

Springfield, VA 22161

Telephone: 1-800-553-6847 or

(703) 605-6000

Fax: (703) 321-8547

Internet: http://www.ntis.gov/ordering.htm 


\title{
High-frequency Probing Diagnostic for Hall Current Plasma Thrusters
}

\author{
A.A. Litvak, Y. Raitses, and N.J. Fisch \\ Princeton Plasma Physics Laboratory, \\ Princeton University, Princeton, NJ 08543
}

\begin{abstract}
High-frequency oscillations (1-100 MHz) in Hall thrusters have apparently eluded significant experimental scrutiny. A diagnostic setup, consisting of single Langmuir probe, special shielded probe connector-positioner, and electronic impedance-matching circuit, was successfully built and calibrated. Through simultaneous high-frequency probing of the Hall thruster plasma at multiple locations, high-frequency plasma waves have been identified and characterized for various thruster operating conditions.
\end{abstract}




\section{INTRODUCTION}

Hall thrusters are now considered as the preferred candidate for spacecraft propulsion in certain near-Earth missions. One of the important issues that could stand in the way of successful integration of the Hall thruster in spacecraft [1] is the presence of plasma oscillations, which could interfere with RF communication, or the thruster operation itself. Both theoretical and experimental studies of plasma oscillatory behavior have been performed since the earliest Hall thruster investigations [2] and are still under way [3].

In spite of widely recognized importance of the oscillations in the high-frequency band for thruster operation, the insight on the physical properties of these modes is very limited both theoretically and experimentally [4]. Lack of experimental data regarding plasma instabilities with the frequencies of a few tens of $\mathrm{MHz}$ is apparently due to technical difficulties one encounters in detecting and diagnosing these modes.

This paper is organized as follows. The technical problems encountered in diagnosing of high-frequency phenomena in a Hall thruster plasma are discussed in Section II. Section III describes the instrument setup which allows to detect and characterize high-frequency oscillations inside a laboratory Hall thruster, while Section IV describes the calibration and experimental procedures for high-frequency measurements. 


\section{HIGH FREQUENCY PROBE DIAGNOSTIC}

Measurements of the plasma oscillations in this frequency range have become feasible due to recent progress in the fabrication of miniaturized semiconductor devices. Use of such devices allows placement of the signal conditioning electronics inside the vacuum vessel in the proximity of the probe, needed to achieve acceptable signal-to-noise ratio. Such measurements were recently successfully performed, for example, in the Magnetic Reconnection eXperiment [5], however Hall thrusters present additional problems for the use of probe diagnostics. For example, use of the double probe in Hall thrusters is restricted by sputtering of the probe material, which can produce a short-circuit between the probe tips. Also, double probe characteristics are very difficult to interpret in the presence of a magnetic field and for a flow of ions with an unknown energy distribution. For larger Hall thrusters, the use of the coil-type antenna for the detection of such oscillations might be feasible, but, in thruster models with the overall channel diameter less than $10 \mathrm{~cm}$, localized measurements will require antenna sizes of $\sim 1 \mathrm{~mm}$ diameter. Such an antenna would be very difficult to implement technically due to short lifetime in harsh environment of Hall thruster plasma, and may not yield a sufficient level of detected signal due to small pick-up area of the antenna.

The single Langmuir probe is one of the most commonly used plasma diagnostic tools, but it too has very serious constraints while used to study Hall thruster plasma. Probes inside the acceleration channel tend to disturb the discharge. It is also difficult to maintain probe integrity inside high-temperature region [6]. Thus, the only accessible 
fixed location of such probing is on the outer wall of the ceramic channel close to the channel exit. At the same time, probe tip size must obey [7], $r<<\rho_{e}$, where $r$ is the probe radius and $\rho_{\mathrm{e}}$ is the electron gyro-radius. For the typical laboratory Hall thruster (1kW power range) with applied magnetic field of a 100-200 Gs and discharge voltage of 200-300 V the diameter of the probe tip should then not exceed $0.5 \mathrm{~mm}$ on the outer wall of the acceleration channel.

The amount of current, collected by the surface of such a small probe, even for the steady-state measurements is such, that the impedance of the probe-to-plasma interface is of the order of $100 \mathrm{kOhm}$ (the ratio of probe floating potential to the probe ion saturation current). At the same time, the oscillations in the frequency range around $30 \mathrm{MHz}$ correspond to relatively short wavelengths $\sim 1 \mathrm{~m}$ in free space and even shorter in the coaxial cables. This means that all transmission of the signal from the probes to the recording point (oscilloscope, spectrum analyzer etc.) should be performed by the way of coaxial shielded transmission lines with matched impedance. This condition is very difficult to meet using standard low-impedance cables. Therefore, a matching circuit should be constructed and placed close to the probe to minimize the effect of impedance mismatch between the probe and the cables.

During steady state thruster operation the probe tip is bombarded by energetic ions which erodes the probe. Therefore the probe system should accommodate the easy replacement of the probe tip and easy adjustment of its protrusion into the channel. 


\section{INSTRUMENTAL SETUP}

To overcome the limitations and technical difficulties of operating high-frequency probes in the harsh Hall thruster environment, the following probe diagnostic was successfully developed and tested.

The probe is constructed of Tungsten wire $0.25 \mathrm{~mm}$ dia, protruding into the discharge area of the thruster from the outer ceramic wall of acceleration channel. On the outside of the thruster, the probe wire is insulated by alumina tube $0.8 \mathrm{~mm}$ dia. To prevent the probe wire from the pickup of electromagnetic noise, outside the thruster a Molybdenum tube shields the alumina, essentially providing a coaxial transmission channel for the signal from the probe. On the other end the probe wire is coupled to a regular coaxial cable (silicone-coated for vacuum compatibility) through a specially designed connector (Fig. 1). This connector by a single bolt on the back allows easy regulation of the length of the probe protruding into the plasma. The connector is also easy to disassemble in-situ for probe wire replacement. Both of these features are necessary to compensate for fast erosion of the probe tip during thruster operation. At the same time the connector is designed in such way that the whole transmission line stays coaxially shielded.

Oscillations in the plasma density can be related to the oscillations in the ion saturation current of the probe. After the probe setup (without circuitry) was assembled, the I-V characteristics (e.g. Fig. 2) of the probe were experimentally measured at various 
operating points. The analysis of the probe characteristics indicated that, for the probe located in the acceleration zone of the thruster channel, the necessary bias, negative in relation to the probe floating potential, can be provided simply by connecting the probe to the ground through a load, small compared to the probe-plasma impedance, while large enough to detect fluctuations without need for high-amplification techniques. At the same time, the design of the circuit for high-frequency matching of the transmission lines allowed the use of additional biasing voltage, if necessary.

To match the probe setup to the transmission line (e.g. regular 50 Ohm coaxial cable) a matching circuit was designed and assembled (Fig. 3). In this circuit a commercial highspeed transformer is introduced to insulate galvanically the probe immersed in the highvoltage thruster plasma from the recording DSO and provide necessary bandpass filtering. The transformer, loaded by a low-inductance resistor is connected to the input of the high-speed operational amplifier, which provides matching to the coaxial cable, connected to a data recording commercial DSO with matching input impedance.

The following electronic components were selected: Pulse Engineering transformer PE5154CT with the frequency band $0.9-110 \mathrm{MHz} 10 \mathrm{kOhm}$ load resistor, and BurrBrown Operational Amplifier OPA-682 with $10^{5}$ Ohm input and $<1$ Ohm output impedances, and $<250 \mathrm{MHz}$ bandwidth. The signal was recorded using LeCroy LT-264M Digital Storage Oscilloscope. 
Note, that while this system s impedance is perfectly matched between the matching circuit and the DSO, the impedances between the probe and the circuit change significantly. In order to minimize the effect of such mismatch on the signal strength and possible noise introduction, the distance between the probe and the matching circuit should be minimized. This was achieved by placing the matching circuit in a capsule inside a well, protruding from the side of the vacuum chamber toward the thruster (Fig. 4).

In order to provide reliable operation of the matching circuitry in a thermally stable regime in a limited volume of the capsule, mildly pressurized air supply is provided to the capsule for convective removal of the excessive heat.

\section{EXPERIMENTAL PROCEDURE}

The performance of the matching circuit was tested using commercial Wavetek signal generator. For the input signal frequency range 1-50MHz and signal amplitude 5-1000 $\mathrm{mV}$ the response was linear with the introduced noise smaller than the oscilloscope digitizing error.

The system was then used to perform experiments characterizing plasma oscillations in the Hall thruster discharge. The signal from the probing system was recorded by the DSO at the rate of $1 \mathrm{GS} / \mathrm{s}$ with the duration of the samples up to 50 microseconds. The 
recorded signal was afterwards Fourier-analyzed (see, for example, Fig. 5) to obtain data on the oscillatory modes, present in the discharge plasma.

The same setup, but using multiple probes, provided information on the phase velocity and propagation direction of the recorded plasma waves. During multiple experiments with various conventional and non-conventional thruster configurations [8,9] highfrequency plasma waves were detected. The frequencies of the observed waves varied between 5 and $30 \mathrm{MHz}$ depending on the thruster configuration and operating point, and at times several higher-order harmonics were also observed.

The experimental data obtained from multi-probe setup provides clear indication of the presence of frequency- and phase-correlated oscillations at different locations within the thruster at different operating conditions. The results of the measurements are currently being analyzed to provide more complete picture of oscillatory processes in Hall plasma, as well as to compare it with the theoretical predictions for the oscillations in this waveband $[10,11]$.

\section{SUMMARY}

The experimental setup, consisting of adjustable cylindrical single Langmuir probe, fully shielded transmission line and specially designed matching circuitry, was developed and implemented. Such a system allowed experimental measurements of oscillations in the 
severe conditions of steady-state Hall thruster plasma in the frequency band of 1 to 50 $\mathrm{MHz}$, with successful determination of the excited modes frequency and phase properties. Such a probing technique should allow gathering of new experimental data essential to better understanding oscillatory behavior of Hall thrusters.

\section{ACKNOWLEDGEMENTS}

The authors wish to thank Dr. T. Carter and Dr. F. Trintchouk for useful discussions regarding matching problems and electronic components, and Dr. A. Kostrov for discussions on various plasma diagnostic techniques. The authors are indebted to R. Yager and G. Rose for excellent technical support. Thanks also go to Mr. David Staack and Mr. Artem Smirnov for their help with the experiments.

This work was supported by the U.S. DOE under Contract No. DE-ACO2-76-CHO3073. 


\section{REFERENCES}

1. V.V. Zhurin, H.R. Kaufman HR, R.S. Robinson, Plasma Sources Sci. Technol., 8, R1 (1999).

2. G.S. James and R.S. Lowder, Phys. Fluids, 9, 1115 (1966).

3. M.A. Cappelli, W.A. Hargus, Jr., and N.B. Meezan, IEEE Trans. on Plasma Science (submitted).

4. E.Y. Choueiri, Phys. Plasmas, 8, 1411 (2001).

5. T. Carter, H. Ji, F. Trintchouk, M. Yamada, and R.M. Kulsrud, Phys. Rev. Letters (submitted).

6. J.M. Haas, G.G. Spanjers, K. McFall, R.A. Spores, in Proceedings of the 34th Joint Propulsion Conference, Cleveland, Ohio, 1998 , AIAA 98-3656 (American Institute of Aeronautics and Astronautics, Washington, DC, 1998).

7. W. Lochte-Holtgreven, Plasma Diagnostics (American Institute of Physics, 1995).

8. Y. Raitses, L.A. Dorf, A.A. Litvak, N.J. Fisch, J. Appl. Phys., 88, 1263 (2000).

9. N.J. Fisch, Y. Raitses, L.A. Dorf, A.A. Litvak, J. Appl. Phys, 89, 2040 (2001).

10. A.A. Litvak and N.J. Fisch, Phys. Plasmas, 8, 651 (2001).

11. A.A. Litvak and N.J. Fisch, Rayleigh instability in Hall plasma thruster, to be submitted. 


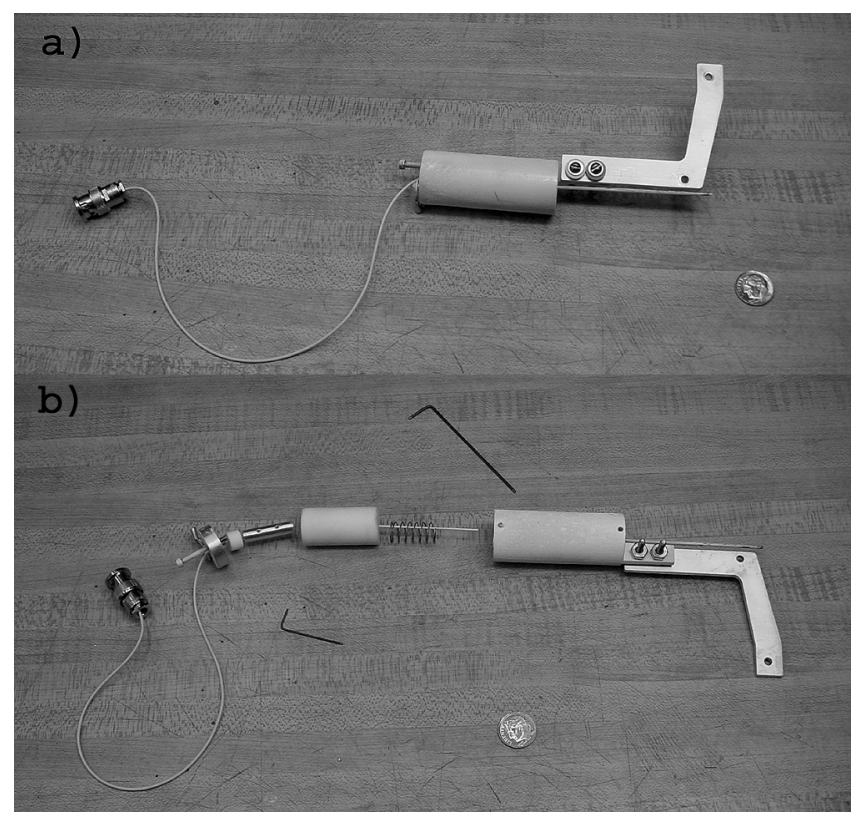

Fig. 1. Probe connector-positioner with mounting bracket:

a) fully assembled; b) disassembled for probe wire change 


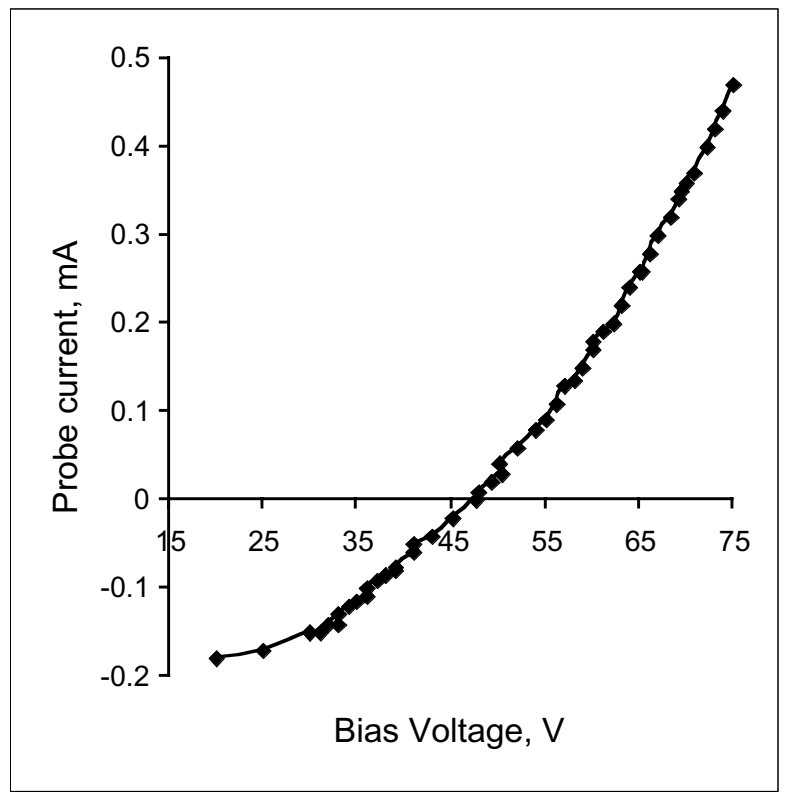

Fig. 2. Probe $I-V$ characteristic - mass flow $1.7 \mathrm{mg} / \mathrm{s} X e, V_{d}=200 V, I_{d}=1.6 A, I_{\text {coil }}=1.5 A$ 


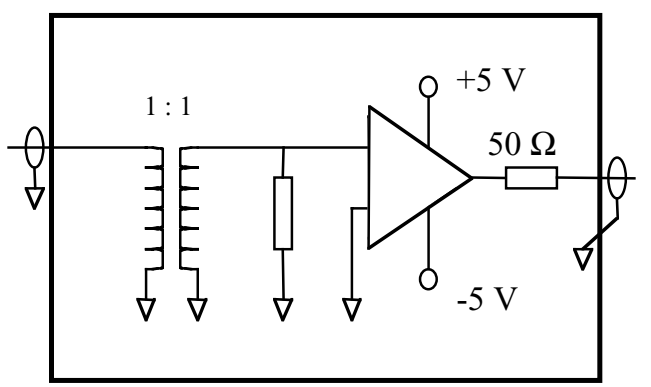

Fig 3. Impedance-matching circuit diagram 


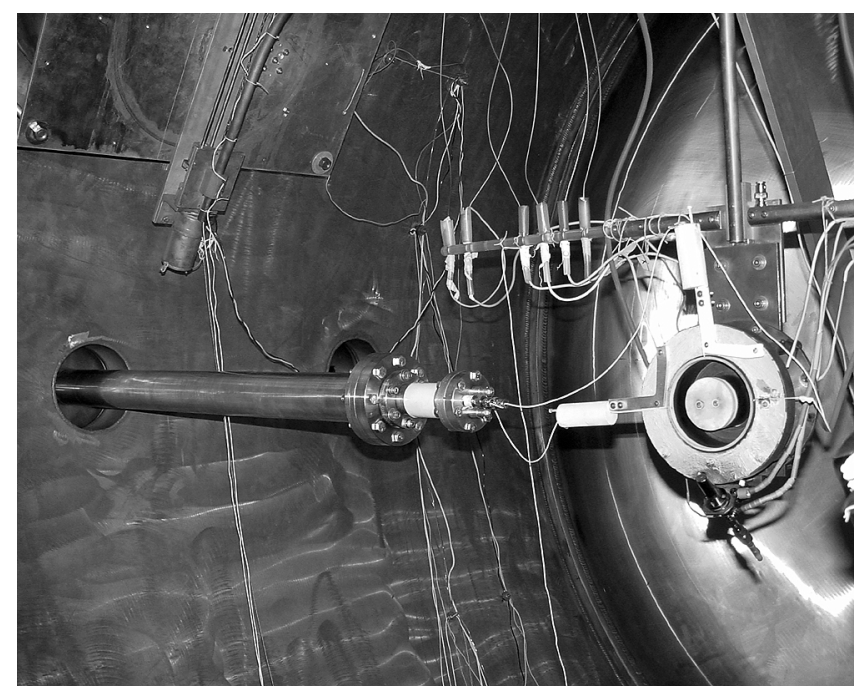

Fig 4. Two probes connected to the matching circuit inside a tube well 


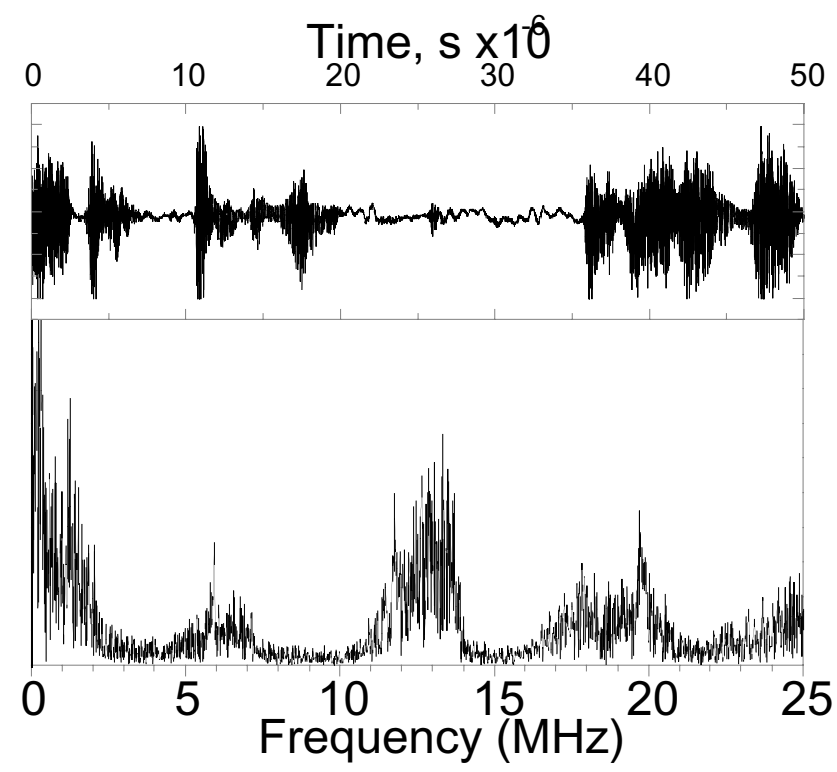

Fig. 5. Typical oscilloscope trace and corresponding frequency spectrum 


\section{External Distribution}

Plasma Research Laboratory, Australian National University, Australia

Professor I.R. J ones, Flinders University, Australia

Professor J oão Canalle, Instituto de Fisica DEQ/IF - UERJ , Brazil

Mr. Gerson O. Ludwig, Instituto Nacional de Pesquisas, Brazil

Dr. P.H. Sakanaka, Instituto Fisica, Brazil

The Librarian, Culham Laboratory, England

Library, R61, Rutherford Appleton Laboratory, England

Mrs. S.A. Hutchinson, JET Library, England

Professor M.N. Bussac, Ecole Polytechnique, France

Librarian, Max-Planck-Institut für Plasmaphysik, Germany

J olan Moldvai, Reports Library, MTA KFKI-ATKI, Hungary

Dr. P. Kaw, Institute for Plasma Research, India

Ms. P.J . Pathak, Librarian, Insitute for Plasma Research, India

Ms. Clelia De Palo, Associazione EURATOM-ENEA, I taly

Dr. G. Grosso, Instituto di Fisica del Plasma, Italy

Librarian, Naka Fusion Research Establishment, J AERI, J apan

Library, Plasma Physics Laboratory, Kyoto University, J apan

Research Information Center, National Institute for Fusion Science, J apan

Dr. O. Mitarai, Kyushu Tokai University, J apan

Library, Academia Sinica, Institute of Plasma Physics, People's Republic of China

Shih-Tung Tsai, Institute of Physics, Chinese Academy of Sciences, People's Republic of China

Dr. S. Mirnov, TRINITI, Troitsk, Russian Federation, Russia

Dr. V.S. Strelkov, Kurchatov Institute, Russian Federation, Russia

Professor Peter Lukac, Katedra Fyziky Plazmy MFF UK, Mlynska dolina F-2, Komenskeho Univerzita, SK-842 15 Bratislava, Slovakia

Dr. G.S. Lee, Korea Basic Science Institute, South Korea

Mr. Dennis Bruggink, Fusion Library, University of Wisconsin, USA

Institute for Plasma Research, University of Maryland, USA

Librarian, Fusion Energy Division, Oak Ridge National Laboratory, USA

Librarian, Institute of Fusion Studies, University of Texas, USA

Librarian, Magnetic Fusion Program, Lawrence Livermore National Laboratory, USA

Library, General Atomics, USA

Plasma Physics Group, Fusion Energy Research Program, University of California at San Diego, USA

Plasma Physics Library, Columbia University, USA

Alkesh Punjabi, Center for Fusion Research and Training, Hampton University, USA

Dr. W.M. Stacey, Fusion Research Center, Georgia Institute of Technology, USA

Dr. J ohn Willis, U.S. Department of Energy, Office of Fusion Energy Sciences, USA

Mr. Paul H. Wright, Indianapolis, Indiana, USA 
The Princeton Plasma Physics Laboratory is operated by Princeton University under contract with the U.S. Department of Energy.

\author{
Information Services \\ Princeton Plasma Physics Laboratory \\ P.O. Box 451 \\ Princeton, NJ 08543
}

Phone: 609-243-2750

Fax: 609-243-2751

e-mail: pppl_info@pppl.gov

Internet Address: http://www.pppl.gov 